\title{
How Mobile Technology Can Be Used to Develop Real-Time Animal Disease Surveillance in Indonesia?
}

\author{
Achmad Fadillah \\ School of Business \\ IPB University (Bogor Agricultural \\ University) \\ Bogor, Indonesia \\ achmadfadillah@apps.ipb.ac.id
}

\author{
Arif Imam Suroso \\ School of Business \\ IPB University (Bogor Agricultural \\ University) \\ Bogor, Indonesia \\ arifimamsuroso@apps.ipb.ac.id
}

\author{
Dikky Indrawan \\ School of Busines \\ IPB University (Bogor Agricultural \\ University) \\ Bogor, Indonesia \\ rdikky@apps.ipb.ac.id
}

\begin{abstract}
Setting up a real-time early warning system based on animal disease surveillance in Indonesia is difficult, since Indonesia is a vast archipelago with many islands. Mobile technology offers new opportunities for disease reporting. However, the development of mobile technology for animal disease surveillance has no roadmap to develop its information technology framework. This paper aims to present a conceptual framework of a mobile smartphone-based frontline surveillance system development in Indonesia. The framework included assistance in data collection for increasing the quality of animal disease surveillance reports. This paper described possible new technologies using the participatory approach. The overview of the best practices of animal surveillance programs implemented by the Food Agriculture Organization (FAO) and the Indonesia Ministry of Agriculture (MOA) was given comprehensive suggestions for future development. The roadmap of animal disease surveillance development shows the sustainability potential of mobile technology-based for animal disease surveillance in Indonesia. The development of human resources and increased communication between stakeholders were important for successful implementation. This paper can be seen as guidance to the animal disease early warning system in Indonesia.
\end{abstract}

Keywords-early warning system, animal disease surveillance, mobile technology, roadmap

\section{INTRODUCTION}

Animal disease surveillance programs in Indonesia have not been effective. There was still a lack of effective surveillance program. It can be seen from the many outbreak events that were not quickly handled by relevant stakeholders. One of the surveillance programs that already carried out by the government was a surveillance program and participatory disease response of avian influenza outbreaks in Indonesia [1]. Based on the Ear [2], there were various challenges in setting up surveillance infrastructure systems in Indonesia, such as economic, political, and cultural challenges. In addition, the lack of timely reporting of animal disease events, especially avian influenza cases still occur in South-East Asia and Western Pacific Regions including Indonesia [3].
Based on Wibawa and Satoto [4], there are several causes of the difficulty of dealing with outbreaks and spread of disease transmitted by animals such as underreporting animal diseases, poor surveillance, and lack of coordination among stakeholders and sectors. Underreporting of actual cases across the regency became one of the factors spreading animal disease in Indonesia [5].

Underreporting and lack of animal disease surveillance were the causes of emerging diseases and further spread of endemic. According to Coker, et al [6] South-east Asia has challenges in controlling emerging diseases, ranging from identifying factors that influence the emergence of disease, to creating appropriate surveillance and surveillance systems, and ensuring governance mechanisms work effectively to improve control interventions of animal disease. In the past decade, several outbreaks of animal disease occurred in Indonesia such as the epidemic of dengue transmission in southern Sumatra [7], endemic chikungunya virus infections in Bandung [8], avian influenza and rabies in several regions in Indonesia [9]. The trends of chikungunya, rabies, and avian influenza reported cases in Indonesia 2006-2015 based on the ProMED-mail and Ministry of Health Republic of Indonesia database can be seen in Fig. 1.

\section{Chikungunya (CHIKV)}

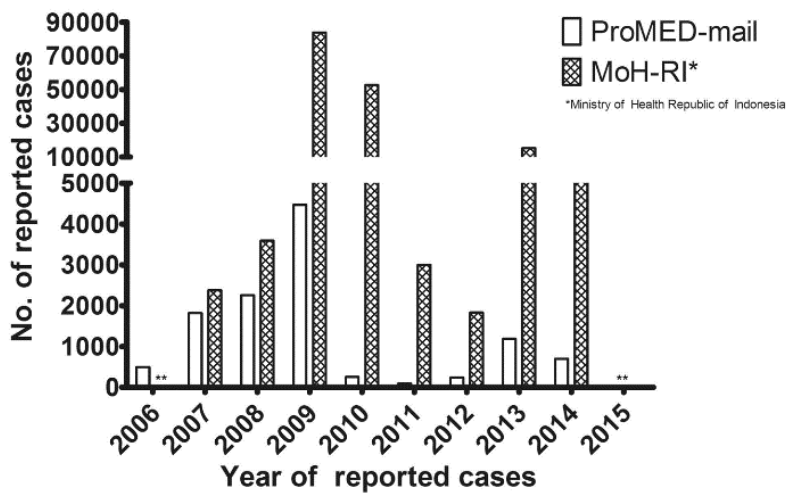

(a) 


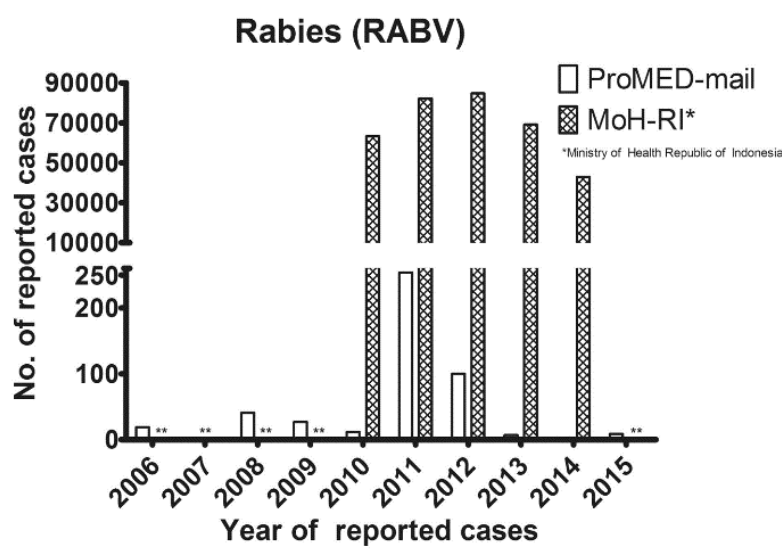

(b)

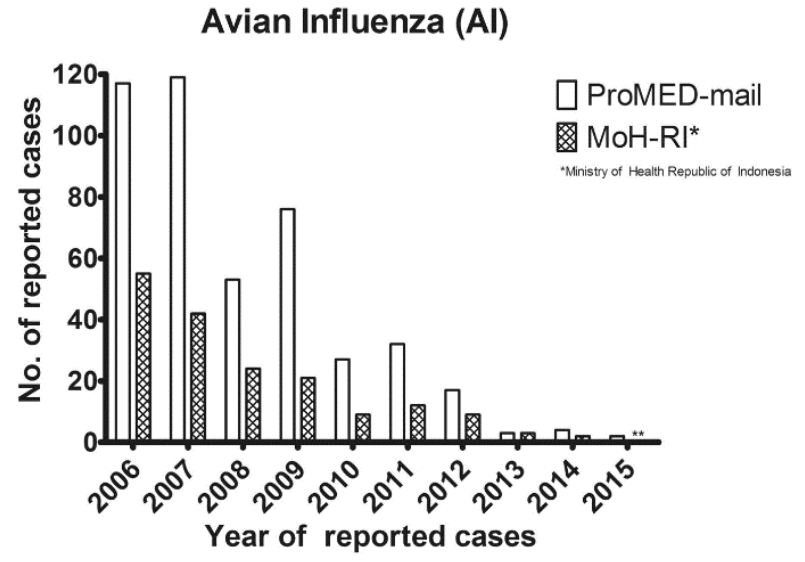

(c)

Fig. 1. Trends of chikungunya (a), rabies (b), and avian influenza (c) reported cases in Indonesia 2006-2015 [9]

Setting up real-time early warning systems based on animal disease surveillance in Indonesia was very difficult since Indonesia is a vast archipelago with many islands. Mobile technology is offered new opportunities for disease reporting. Based on Karimuribo, et al [10], a mobile technology (AfyaData) can be developed as an innovative animal disease participatory community-based surveillance in Africa. Information and communication technology (ICT) - based mobile applications can detect animal diseases and can increase the effectiveness of surveillance of animal diseases at the national, regional and global levels. Animal disease surveillance systems were designed to provide accurate information for local and national governments and as the guideline for giving incentives to relevant stakeholders (local animal health workers and animal owners) to report real-time information on animal diseases to avoid underreporting problems [11].

The development of mobile technology for animal disease surveillance in Indonesia was supported by the development of information technology. Based on digital data [12], mobile subscriptions in Indonesia reached 355.5 million (or $133 \%$ of the total population) and the number of internet users reached 150 million $(56 \%$ of the total population). Meanwhile, the percentage of mobile phone users reached $91 \%$ and smartphone users reached $60 \%$ in 2019. The development of digital and information technology is very good to support animal disease surveillance based on mobile technology in Indonesia.

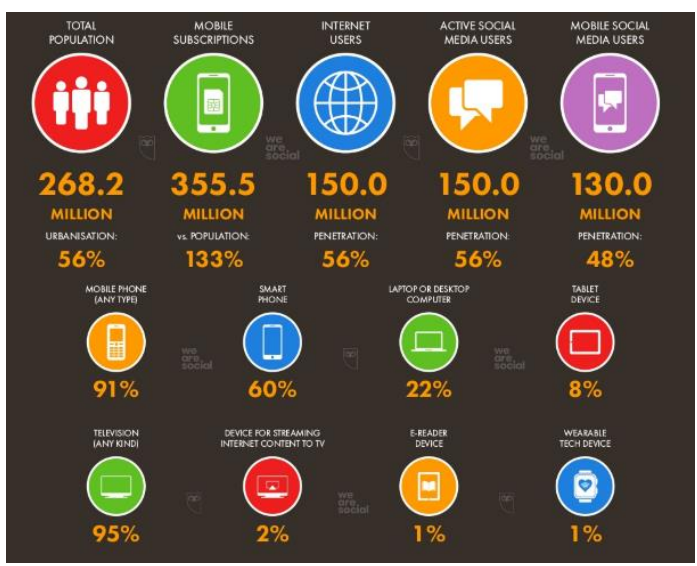

Fig. 2. Digital and device usage in Indonesia 2019 [12]

However, the development of mobile technology for animal disease surveillance in Indonesia has no clear roadmap to develop its information technology framework. This paper aims to present a conceptual framework and best practices of a mobile technology-based animal disease surveillance system development in Global and Indonesia.

\section{METHODS}

The research was focused on real-time animal disease surveillance in Indonesia using mobile technology. The research uses data from the Food and Agriculture Organization (FAO) and the Indonesian Ministry of Agriculture (MoA) for qualitative and descriptive analysis. The conceptual framework also comes from best practices of mobile technology-based animal disease surveillance implemented by the Food and Agriculture Organization (FAO) and the Indonesian Ministry of Agriculture (MoA).

\section{RESULTS}

The World Health Organization (WHO) and Food Agriculture Organization (FAO) have developed the frameworks to improve animal disease information sharing across sectors to prevent animal disease outbreaks [13]. The application of mobile technology in real-time animal disease surveillance was still focused on studies at the national, regional and global levels. Some institutions have tried to implement animal disease surveillance based on mobile technology, such as the Food and Agriculture Organization (FAO) and the Indonesian Ministry of Agriculture (MoA). The following were the overview of the application of animal disease surveillance implemented by FAO and MOA.

A. Overview of global mobile technology application for animal disease surveillance developed by FAO

FAO developed a mobile application to collect epidemiological data from the field. Empres-i Event Mobile Application (EMA) functions to report in real-time animal diseases and outbreaks to enhance surveillance [14]. Empres-i EMA database can display a map of the location of animal disease outbreaks. In addition, the EMA Empres-i display can display trend data in graphical form to facilitate data analysis. The appearance of the EMA Empres-i website developed by FAO can be seen in Fig. 3 . 


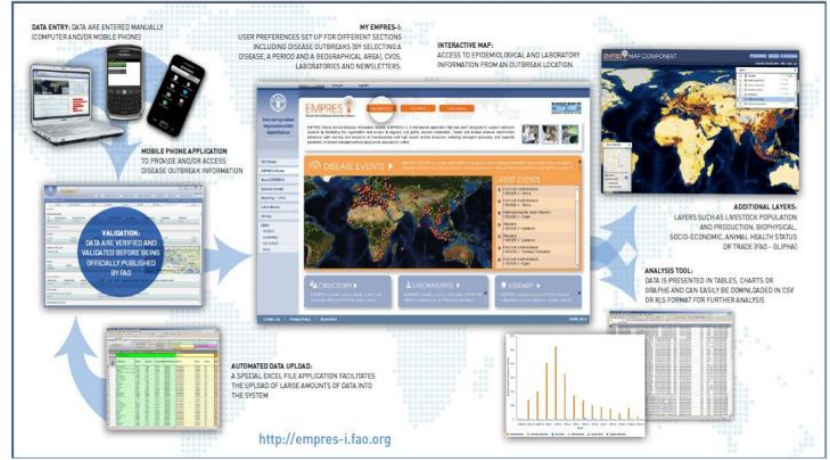

Fig. 3. Website appearance of Empres-i EMA FAO [15]

Empres-i EMA can provide early warning notifications at the local and country levels. District veterinary officers (DVOs) report animal disease events through smartphone applications and submit draft reports to the relevant surveillance team via the Empres-i platform. Validated reports are then conveyed to various stakeholders (local government, decision-makers, DVOs, and other users. The workflow business process of Empowerment-EMA which is developed by FAO can be seen in Fig. 4.

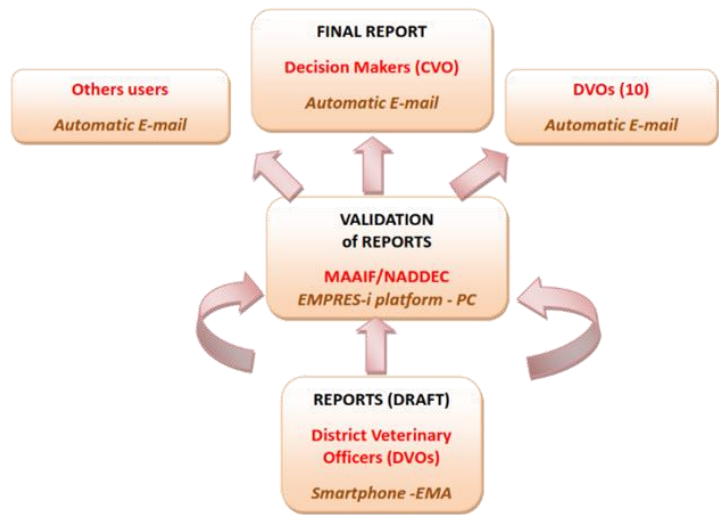

Fig. 4. The workflow business process of Empres-i EMA FAO

Animal owners and officers in the field can upload one or more photos related to animal disease events or outbreak information in specific locations through mobile applications, especially in the android mobile. Animal owners and officers can fill in the information on the time of occurrence, status diagnosis, animal disease types, animal disease subtypes, and source diagnosis. The mobile application display of EMA FAO can be seen in Fig. 5.
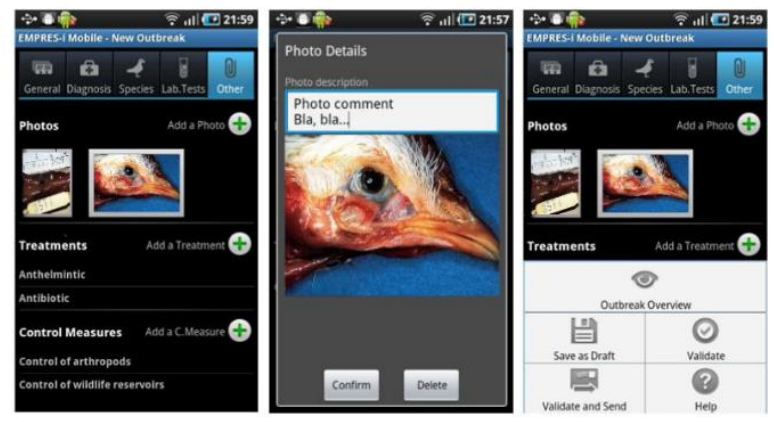
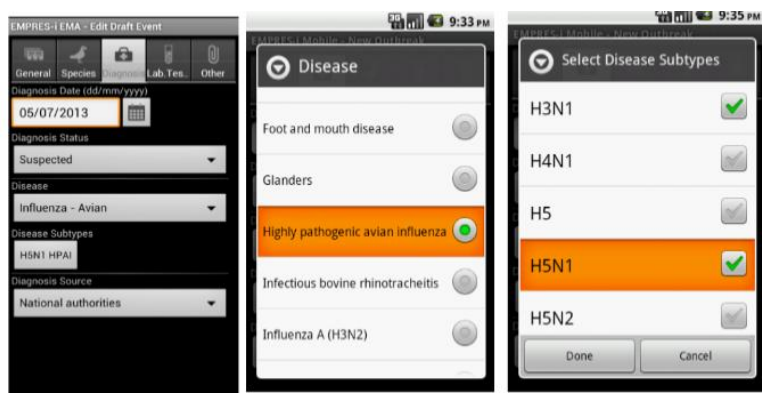

Fig. 5. Mobile appearance of EMA FAO

\section{B. Overview of national integrated animal health} information system (iSIKHNAS)

The Indonesian Ministry of Agriculture (MoA) has also developed information systems for animal disease surveillance. The information system was a national integrated animal health information system (iSIKHNAS). The iSIKHNAS provides a flexible and sustainable platform for the collection, management and use of livestock and animal health and surveillance data [16]. SMS, email, website, and mobile phone application were used by users to interact in real-time in iSIKHNAS. iSIKHNAS developed by MOA has several principles: providing notification to those who need it, reporting in real-time every animal disease event and outbreaks, integrated, capturing validated data, and real-time. The overview of the flow of data input and reporting processes in iSIKHNAS through various media (SMS, websites, e-mail, information systems, and mobile phone applications) can be seen in Fig. 6. Farmers, officers, and users input the data and report animal disease events in the system iSIKHNAS information and data processed to local government (district and provincial services), central government (MOA), and other users.

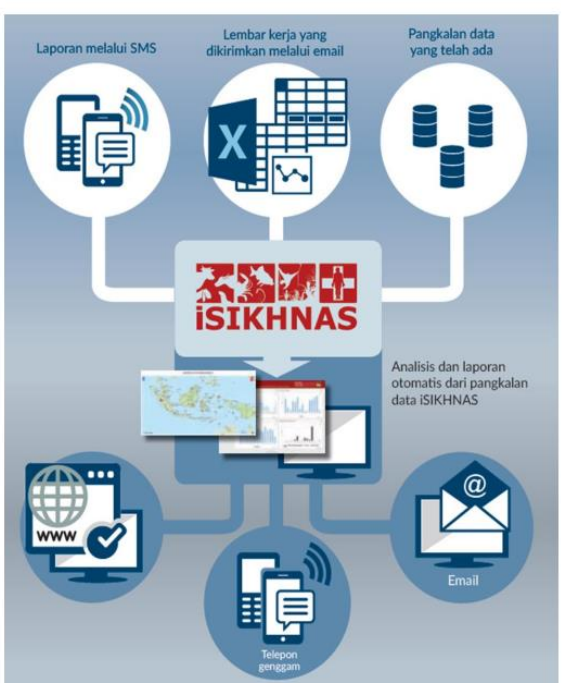

Fig. 6 An overview of the reporting process flow in iSIKHNAS through various tools [16]

The total number of users of iSIKHNAS reached $5,029,377$ users, consist of 5,008,796 farmers and 20,581 officers from 34 provinces in Indonesia. An increasing trend in the number of registered users of iSIKHNAS occurred from 2016 to 2017. In 2016 the additional number of farmers was only 10,437 users and the additional number of officers was only 4,187 users. Whereas in 2017, the additional 
number of farmers reached 2,662,231 users and the additional number of officers reached 6,376 users. The trend of an increasing the number of iSIKHNAS users during 2016-2018 can be seen in Fig. 7.

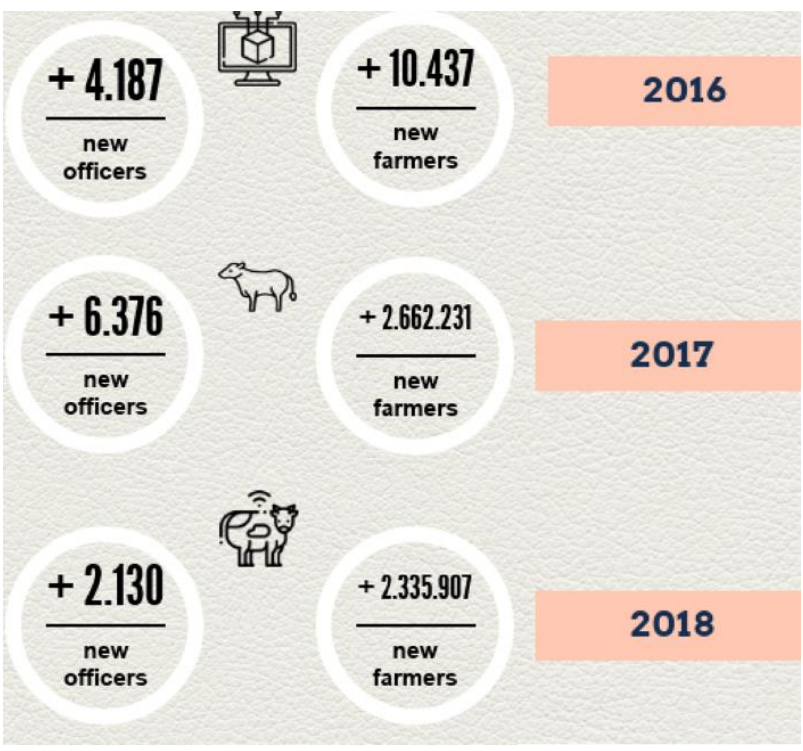

Fig. 7 The trend of user numbers of iSIKHNAS during 2016-2018 [17]

Based on MOA data [17], in 2018, iSIKHNAS received $1,144,185$ animal health reports. Animal health reports were dominated by disease treatment and case development $(58.94 \%)$, followed by animal disease reports $(33.37 \%)$, animal movement $(5.53 \%)$, and vaccination $(1.38 \%)$. The detail of the percentage of animal health reports in 2018 can be seen in Fig. 8 .

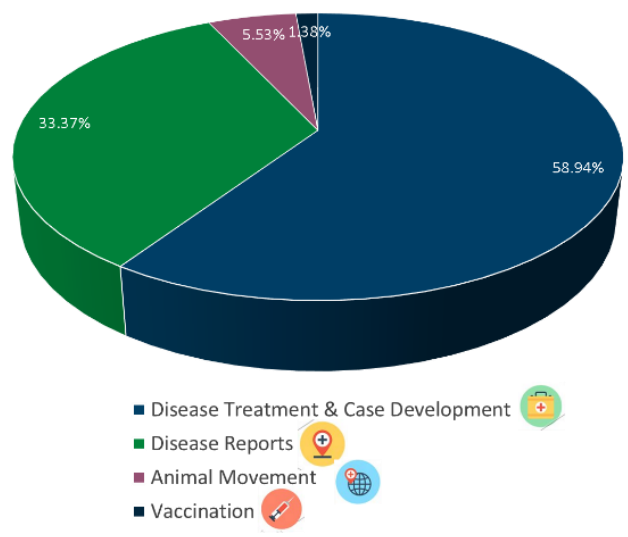

Fig. 8. Number of animal health reports in 2018

Based on iSIKHNAS animal health reports, around $96 \%$ of reported disease cases have been treated and $71 \%$ of treated cases were monitored and reported further to the iSIKHNAS system [17]. The syndrome/animal disease report priorities in Indonesia showed that Rabies dominated the report in iSIKHNAS and was followed by Anthrax (Fig. 9).

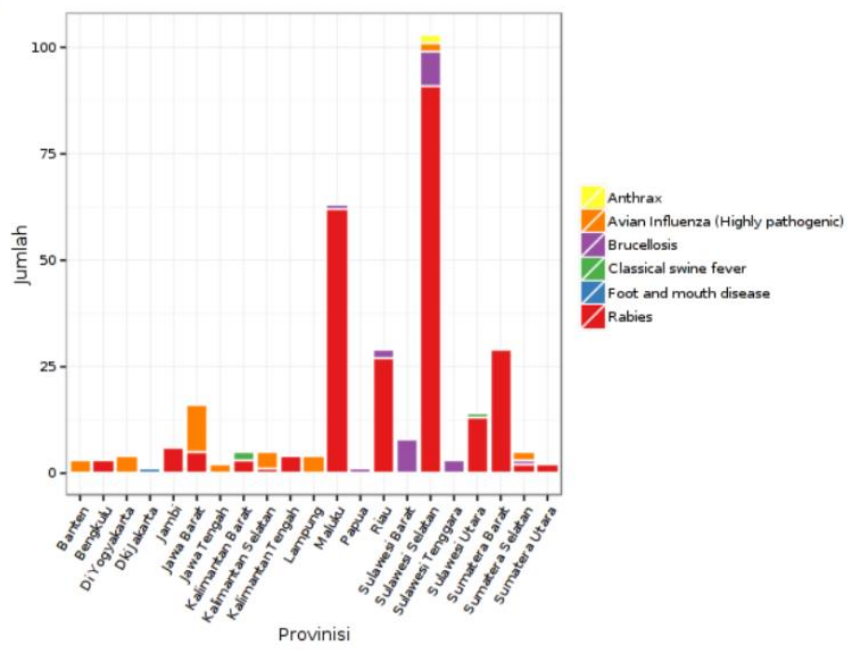

Fig. 9. Syndrome/animal disease report priorities in Indonesia 2018 [18]

\section{DISCUSSION}

The mobile technology has advantages and challenges in monitoring and controlling animal diseases at global, regional, and national levels. The application of mobile technology in animal disease surveillance programs continues to grow rapidly in the past decades. The use of information and communication technology can facilitate various stakeholders to collect, process, analyze and collect complete and comprehensive data of animal health and disease.

Based on animal surveillance best practices conducted by FAO in various countries (Namibia, Zambia, Mozambique, Tanzania, Armenia, Azerbaijan, Georgia, Turkey, and Uganda), the application of mobile technology can be used as a real-time animal disease surveillance. There are several challenges in the development of technology-based mobile disease surveillance animals: quality and validation of data, lack of investment for program sustainability, quick response and action of animal disease outbreak, and community/officer incentives [19].

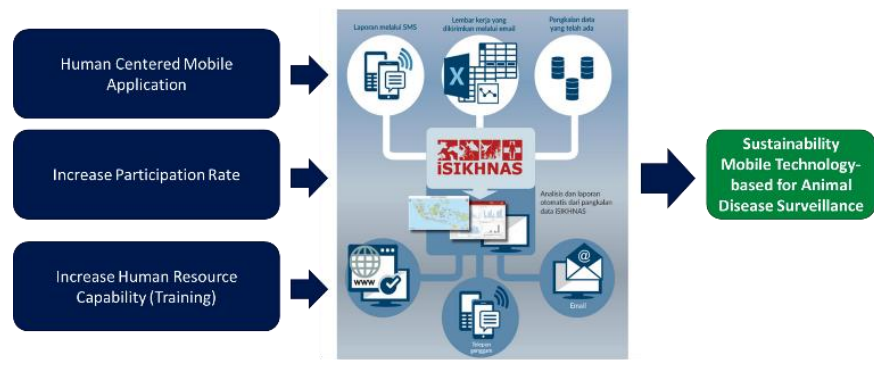

Fig. 10. The future development of animal disease surveillance in Indonesia

There are several challenges in development of mobile technology-based animal disease surveillance in Indonesia: improving data collection validity and quality, increasing the quality of real-time animal disease data, data integration between central and regional systems, data analysis of disease emergence and spread for quick actions/programs, collaboration and investment for program sustainability, and incentives for reporting to increase community participation in the system. The proposed future development of animal disease surveillance in Indonesia can be seen in Figure10. 
The future development of animal disease surveillance in Indonesia was developed from a pre-existing information system platform (iSIKHNAS). Some suggestions for developing animal surveillance were the development more focused on human-centered mobile applications, increase participation rate of users, and increase human resource capability (training). The target of future development was the sustainability of mobile technology-based for animal disease surveillance.

\section{CONCLUSIONS}

Based on FAO and Indonesia MoA's best practices overview, mobile technology can be used to develop realtime animal disease surveillance in global and Indonesia. Mobile technology also can be used as an animal disease early warning system in Indonesia. The selection of appropriate tools and workflow, the collection of good quality (valid) data, and the information technology infrastructure are needed to develop a roadmap of animal disease surveillance in Indonesia. Development of human resources (training) and increased collaboration between stakeholders was important for the successful and sustainable implementation of animal disease surveillance programs in Indonesia.

\section{ACKNOWLEDGMENT}

This research paper was funded by School of Business, IPB University (Bogor Agricultural University). Acknowledgements was also expressed to the ISSESAHSEA committee for conducting and facilitating the international conference.

\section{REFERENCES}

[1] M. Azhar, A.S. Lubis, E.S. Siregar, R.G. Alders, E. Brum, J. McGrane, I. Morgan, P. Roeder. 2009. Participatory Disease Surveillance and Response in Indonesia: Strengthening Veterinary Services and Empowering Communities to Prevent and Control Highly Pathogenic Avian Influenza. Vol. 54, No. 1, Supplement: Proceedings of the Seventh International Symposium on Avian Influenza (March 2010), pp. 749-753. Published by: American Association of Avian Pathologists. https://www.jstor.org/stable/40601152.

[2] S. Ear. 2012. Emerging Infectious Disease Surveillance in Southeast Asia: Cambodia, Indonesia, and the US Naval Area Medical Research Unit 2, Asian Security, 8:2, 164-187, DOI:10.1080/14799855.2012.686338.

[3] [WHO]. World Health Organization, Regional Office for South-East Asia. (2015). National Influenza Centres and Influenza Surveillance in the WHO's South-East Asia and Western Pacific Regions. Report of the eighth bi-regional meeting, Jakarta, Indonesia, 12-15 August 2014. World Health Organization. https://apps.who.int/iris/handle/10665/181591.

[4] T. Wibawa, T. B. T. Satoto. 2016. Magnitude of Neglected Tropical Diseases in Indonesia at Postmillennium Development Goals Era. Journal of Tropical Medicine. https://doi.org/10.1155/2016/5716785.

[5] S. P. M. Wijayanti, S. Sunaryo, S. Suprihatin, M. McFarlane, S. M Rainey, et al. 2016. Correction: Dengue in Java, Indonesia: Relevance of Mosquito Indices as Risk Predictors. PLOS Neglected Tropical Diseases. https://doi.org/10.1371/journal.pntd.0004683.

[6] R. J. Coker, B. M. Hunter, J. W. Rudge, M. Liverani, P. Hanvoravongchai. 2011. Emerging infectious diseases in southeast Asia: regional challenges to control. Elsevier.. https://doi.org/10.1016/S0140-6736(10)62004-1

[7] A. L. Corwin, R. P. Larasati, M. J. Bangs, S. Wuryadi, S. Arjoso, N. Sukri, E. Listyaningsih, S. Hartati, R. Namursa, Z. Anwar. 2001. Epidemic dengue transmission in southern Sumatra, Indonesia. The Royal Society of Tropical Medicine and Hygiene, Volume 95, Issue 3, May-June 2001, Pages 257-265, https://doi.org/10.1016/S00359203(01)90229-9.

[8] H. Kosasih, Q. de Mast, S. Widjaja, P. Sudjana, U. Antonjaya,C. Ma'roef, S. F. Riswari, K. R. Porter, T. H. Burgess, B. Alisjahbana, A. van der Ven, M. Williams. 2013. Evidence for Endemic Chikungunya Virus Infections in Bandung, Indonesia. PLOS: Neglected Tropical Diseases. Published: October 24, 2013. https://doi.org/10.1371/journal.pntd.0002483.

[9] W. de Jong, M. Rusli, S. Bhoelan, S. Rohde, F. A. Rantam, F. A. Noeryoto, U. Hadi, E. C. M. van Gorp, M. Goeijenbier. 2018. Endemic and emerging acute virus infections in Indonesia: an overview of the past decade and implications for the future. Critical Reviews in Microbiology, 44:4, 487-503, DOI: 10.1080/1040841X.2018.1438986.

[10] E. D. Karimuribo, E. Mutagahywa, C. Sindato, L. Mboera, M. Mwabukusi, M. K. Njenga, S. Teesdale, J. Olsen, M. Rweyemamu. 2017. A Smartphone App (AfyaData) for Innovative One Health Disease Surveillance from Community to National Levels in Africa: Intervention in Disease Surveillance. JMIR Public Health Surveill 2017;3(4):e94. DOI: 10.2196/publichealth.7373.

[11] J. Hutchison, Catriona, Mackenzie, B. Madin, J. Happold, E. Leslie, E. Zalcman, A. Meyer, A. Cameron. 2018. New approaches to aquatic and terrestrial animal surveillance: The potential for people and technology to transform epidemiology. Preventive Veterinary Medicine. Volume 167, 1 June 2019, Pages 169-173. https://doi.org/10.1016/j.prevetmed.2018.10.009.

[12] https://wearesocial.com/global-digital-report-2019.

[13] V. Setiawaty, N. L. Dharmayanti, Misriyah, H. A. Pawestri, M. Azhar, G. Tallis, L. Schoonman, G. Samaan. 2014. Avian Influenza A(H5N1) Virus Outbreak Investigation: Application of the FAO OIE - WHO Four - way Linking Framework in Indonesia.. Zoonoses and Public HealthVolume 62, Issue 5. Wiley Online Library. https://doi.org/10.1111/zph.12158.

[14] [FAO]. Food Agriculture Organization. 2015. EMA-i: a mobile app for timely animal disease field reporting to enhance surveillance.. http://www.fao.org/3/a-i4853e.pdf.

[15] http://empres-i.fao.org/.

[16] http://wiki.isikhnas.com/images/9/9a/What_is_iSIKHNAS_v6_ENG. pdf .

[17] [MOA]. Ministry of Agriculture. 2019. iSIKHNAS Usage Report 2018. Surveillance Subdirectorate, Directorate of Animal Health, Directorate General of Livestock and Animal Health Services. Ministry of Agriculture (MOA). Indonesia.

[18] [MOA]. Ministry of Agriculture. 2018. Intregrated real-time animal health and production information system. Directorate of Animal Health, Directorate General of Livestock and Animal Health Services. Ministry of Agriculture (MOA). Indonesia.

[19] http://www.fao.org/fileadmin/user_upload/eufmd/Roadmap_2014_As tana/Mobile_Technologies__Pinto.pdf 